OPEN ACCESS

Edited by:

François Billaut,

Laval University, Canada

Reviewed by:

Paul Marshall,

The University of Auckland,

New Zealand

Tadej Debevec,

University of Ljubljana, Slovenia

${ }^{*}$ Correspondence:

Stefanos Volianitis

svolianitis@qu.edu.qa

Specialty section:

This article was submitted to

Exercise Physiology,

a section of the journal

Frontiers in Physiology

Received: 04 December 2021

Accepted: 11 January 2022

Published: 03 February 2022

Citation:

Volianitis S, Rasmussen P,

Petersen NC and Secher NH (2022)

The Effect of Hyperoxia on Central and Peripheral Factors of Arm Flexor

Muscles Fatigue Following Maximal Ergometer Rowing in Men.

Front. Physiol. 13:829097.

doi: 10.3389/fphys.2022.829097

\section{The Effect of Hyperoxia on Central and Peripheral Factors of Arm Flexor Muscles Fatigue Following Maximal Ergometer Rowing in Men}

\author{
Stefanos Volianitis ${ }^{1 *}$, Peter Rasmussen ${ }^{2}$, Nicolas C. Petersen ${ }^{3}$ and Niels H. Secher ${ }^{2}$ \\ ${ }^{1}$ Department of Physical Education, College of Education, Qatar University, Doha, Qatar, ${ }^{2}$ Department of Anesthesiology, \\ Rigshospitalet, Institute for Clinical Medicine, University of Copenhagen, Copenhagen, Denmark, ${ }^{3}$ Department of \\ Neuroscience, Faculty of Health and Medical Sciences, University of Copenhagen, Copenhagen, Denmark
}

Purpose: This study evaluates the effect of hyperoxia on cerebral oxygenation and neuromuscular fatigue mechanisms of the elbow flexor muscles following ergometer rowing.

Methods: In 11 competitive male rowers (age, $30 \pm 4$ years), we measured near-infrared spectroscopy determined frontal lobe oxygenation $\left(\mathrm{ScO}_{2}\right)$ and transcranial Doppler ultrasound determined middle cerebral artery mean flow velocity (MCA $V_{\text {mean }}$ ) combined with maximal voluntary force (MVC), peak resting twitch force $\left(P_{\mathrm{tw}}\right)$ and cortical voluntary activation (VA $\mathrm{A}_{\mathrm{TMS}}$ ) of the elbow flexor muscles using electrical motor point and magnetic motor cortex stimulation, respectively, before, during, and immediately after 2,000 $\mathrm{m}$ all-out effort on rowing ergometer with normoxia and hyperoxia $\left(30 \% \mathrm{O}_{2}\right)$.

Results: Arterial hemoglobin $\mathrm{O}_{2}$ saturation was reduced to $92.5 \pm 0.2 \%$ during exercise with normoxia but maintained at $98.9 \pm 0.2 \%$ with hyperoxia. The MCA $V_{\text {mean }}$ increased by $38 \%(p<0.05)$ with hyperoxia, while only marginally increased with normoxia. Similarly, $\mathrm{ScO}_{2}$ was not affected with hyperoxia but decreased by $7.0 \pm 4.8 \%$ from rest $(p=0.04)$ with normoxia. The MVC and $P_{\mathrm{tw}}$ were reduced $(7 \pm 3 \%$ and $31 \pm 9 \%$, respectively, $p=0.014)$, while $V A_{\text {TMS }}$ was not affected by the rowing effort in normoxia. With hyperoxia, the deficit in MVC and $P_{\text {tw }}$ was attenuated, while $V A_{\text {TMS }}$ was unchanged.

Conclusion: These data indicate that even though hyperoxia restores frontal lobe oxygenation the resultant attenuation of arm muscle fatigue following maximal rowing is peripherally rather than centrally mediated.

Keywords: rowing, cerebral oxygenation, hyperoxia, maximal voluntary contraction, transcranial magnetic stimulation

\section{INTRODUCTION}

Maximal rowing provokes disturbance to systemic and intramuscular homeostasis (Volianitis and Secher, 2009; Volianitis et al., 2018) that exacerbates pulmonary diffusion limitations and reduces arterial hemoglobin oxygen saturation $\left(\mathrm{SaO}_{2}\right)$ to below $88 \%$ (Nielsen et al., 1998). Such pronounced arterial hypoxemia, combined with the hyperventilation-induced reduction 
in $\mathrm{PaCO}_{2}$ by $8-10 \mathrm{~mm} \mathrm{Hg}$ (Volianitis et al., 2008) and dependent cerebral blood blow $(\mathrm{CBF})$, compromises oxygen cerebral delivery and reduces cerebral mitochondrial oxygen tension by more than $10 \mathrm{~mm} \mathrm{Hg}$ (Nybo and Rasmussen, 2007) that can impair motor performance (Rasmussen et al., 2007). Conversely, when cerebral oxygenation is enhanced with oxygen supplementation rowing performance is improved (Nielsen et al., 1999), suggesting that the performance improvement may be attributed to attenuation of "central fatigue" (Gandevia, 2001), that is, enhanced volitional motor output to locomotor muscles (Nybo and Rasmussen, 2007). Alternatively, the ergogenic effect may stem from enhanced force-generating capacity of the exercising muscles due to processes at, or distal to, the neuromuscular junction (i.e., attenuation of "peripheral fatigue"; Allen et al., 2008), secondary to enhanced arterial oxygen content $\left(\mathrm{CaO}_{2}\right)$ and hence oxygen delivery to muscles (Amann et al., 2006a). Oxygen supplementation attenuates the rate of development of peripheral fatigue provoked both by high intensity whole body exercise (Amann et al., 2006b; Romer et al., 2006; Dominelli et al., 2017) and isolated muscle exercise (Katayama et al., 2007), indicating that the effect is independent of possible attenuation of fatiguing metabolites, secondary to a hyperoxiainduced increase in maximal exercise capacity and, thus, changes in relative work intensity.

The contribution of both central and peripheral fatigue mechanisms is considered when attempting to explain performance fatigability, albeit implications for performance should be approached with caution, as the translation of fatigue mechanisms to human whole body performance is not straightforward (Enoka and Duchateau, 2016). The contribution of central and peripheral mechanisms to neuromuscular fatigue depends on the tested muscle group (Enoka et al., 2011) as shown for the upper and lower limbs (Vernillo et al., 2018), for example, $2 \mathrm{~min}$ MVCs result in central fatigue of the lower limbs, but not of the upper limbs indicating that fatigue mechanisms may be regulated differently and limb specific. The functional significance of such differential contribution of central activation to the force production of different muscle groups can be appreciated with the leg "strength paradox," that is, the strength deficit of a bilateral leg effort, typically $15-20 \%$, compared to the strength expected from the sum of the separate unilateral leg efforts, as observed in rowers (Secher, 1975).

Rowing is unique in using both arms and legs in a synchronous manner (i.e., bilateral leg extension and arm flexion), as opposed to most sports and daily life where the limbs are used alternatively as in, for example, walking and running. The training adaptation of such synchronous movement is reflected in attenuation of the strength deficit of bilateral leg effort in rowers. Indeed, in the very best trained rowers the bilateral leg strength may even surpass the sum of the strength of each leg (Secher, 1975). The comparison between unilateral vs. bilateral leg efforts allows for investigation of differences in muscle mass-related fatigability, as suggested by Rossman et al. (2012) and Koral et al. (2020). In contrast to leg efforts, there is no "strength paradox" when using the arms, that is, the strength measured during simultaneous use of both arms corresponds to the sum of the strength of each arm determined separately (Secher et al., 1988). Taken together, the seemingly differential central motor activation to upper and lower limbs suggests that the legs may be more prone to develop force deficit than the arms in circumstances where central motor activation is challenged, as in maximal rowing. In support, leg strength deficit following maximal rowing has been attributed to supraspinal origin (Husmann et al., 2017). However, data on arm neuromuscular activation following rowing are lacking.

This study evaluated the contribution of central and peripheral factors to elbow flexors fatigue following maximal rowing. Considering the different contribution of centrally and peripherally located fatigue mechanisms of upper and lower limbs (Vernillo et al., 2018), we hypothesized that central factors would be less prevalent compared to peripheral factors in the arms following maximal ergometer rowing. In addition, considering the marked arterial desaturation developed during rowing, a second aim of this study was to evaluate the effect of oxygen supplementation on central vs. peripheral factors of elbow flexor muscle fatigue. A second hypothesis was that oxygen supplementation would attenuate central fatigue by enhancing cerebral oxygenation. Maximal voluntary contraction (MVC), transcranial magnetic stimulation (TMS) of the motor cortex, and electrical stimulation of the motor point (MP) were applied for evaluation of central and peripheral factors of elbow flexor muscles fatigue. Also, $\mathrm{CBF}$, cerebral $\left(\mathrm{ScO}_{2}\right)$ and muscle oxygenation $\left(\mathrm{SmO}_{2}\right)$ evaluations were applied as factors associated with rowing fatigability.

\section{MATERIALS AND METHODS}

\section{Participants}

Eleven healthy males (mean \pm SD age, $30 \pm 4$ yrs.; height, $1.80 \pm 0.03 \mathrm{~m}$; weight, $75.0 \pm 3.1 \mathrm{~kg}$ ), following written informed consent, volunteered to the study as approved by the Ethics Committee of Copenhagen (KF 01287471) and conformed to the Declaration of Helsinki. Sample size calculation was based on changes in cortical voluntary activation following maximal dynamic exercise ( $\Delta \mathrm{VA}_{\mathrm{TMS}},-13 \%$; Rasmussen et al., 2010) and the typical error for the measurement of elbow flexion MVC (ICC, 0.992; Allen et al., 1995) with power of 0.80 and an $\alpha$ of 0.05 . All subjects were recruited from a local rowing club and were well familiarized with maximal ergometer rowing as they had been competing for several years at national/ international level (one was a current World champion and two others were members of the national team).

\section{Experimental Design}

Each subject completed one familiarization and two experimental trials. During the familiarization trial, subjects practiced maximal voluntary isometric elbow flexion with and without TMS and electrical stimulation. "All-out" $2,000 \mathrm{~m}$ rowing on a windbraked ergometer (Concept II, Morrisville, VT, United States) was performed with normoxia [inspiratory $\mathrm{O}_{2}$ fraction $\left(\mathrm{FIO}_{2}\right)$, $0.21]$ and hyperoxia $\left(\mathrm{FIO}_{2}, 0.30\right)$, in a pseudo-randomized counter-balanced order, in two experimental trials separated 
by $1-2$ weeks at the same time of day under consistent laboratory conditions (temperature $22 \pm 1^{\circ} \mathrm{C}$, humidity $50 \pm 10 \%$, barometric pressure $757 \pm 4 \mathrm{mmHg}$ ). While the conditions were not blinded, the participants were naive to the purpose of the study and unaware of the experimental hypotheses. The subjects refrained from strenuous exercise, alcohol, and caffeine for $24 \mathrm{~h}$ prior the investigations and reported to the laboratory after an $8 \mathrm{~h}$ overnight fast. On each trial, the subjects rowed for about $20 \mathrm{~min}$ on the ergometer with an individually chosen pre-race warm-up that were accustomed. Then, submaximal and maximal contractions $(60-100 \%$ MVC) were performed to allow estimation of resting twitch for the calculation of $\mathrm{VA}_{\mathrm{TMS}}$, and the stimulation intensities for MP and TMS were determined (for details see the Neuromuscular Evaluation section). Then, the subjects performed two 4-s MVCs, separated by $2 \mathrm{~min}$ of rest, while still seated on the rowing ergometer. If the difference between these MVCs was $>5 \%$, a third MVC was performed. The largest MVC was taken to represent control muscle strength. For all MVCs subjects were encouraged to apply maximal effort and to try to maintain the same intensity throughout the 4-s period. Hyperoxic air was humidified in a Douglas bag and delivered to the subjects through a two-way low-resistance $\mathrm{T}$ valve (model 2,700, Hans Rudolph, Kansas City, MO, United States) for $5 \mathrm{~min}$ prior to and during rowing. Breath-by-breath $\mathrm{O}_{2}$ consumption $\left(\mathrm{VO}_{2}\right)$ and ventilation (VE) were measured with an online gas analyzer (CPX/D, Medical Graphics, St. Paul, MN, United States) and data averaged over $30 \mathrm{~s}$. During rowing, the subjects were verbally encouraged to perform maximally.

Blood samples were drawn anaerobically from a catheter (20 gauge; $1.1 \mathrm{~mm}$ ) inserted in the radial artery of the non-dominant arm (left, for all subjects) three times at rest, once after 500, 1,000, 1,500 m of rowing and immediately after exercise in heparinized syringes and analyzed immediately for blood gas variables (ABL 725; Radiometer, Copenhagen, Denmark).

\section{Cerebral Perfusion}

Transcranial Doppler ultrasound (2 MHz probe; Multidop X; DWL, Sipplingen, Germany) determined middle cerebral artery mean flow velocity (MCA $V_{\text {mean }}$ ) as an index of $\mathrm{CBF}$, since changes in MCA $V_{\text {mean }}$ reflect those of CBF during dynamic exercise (Secher et al., 2008). The MCA $V_{\text {mean }}$ was the mean velocity of the time-averaged maximal velocity over the cardiac cycle derived from the envelope of the maximum frequencies of the Doppler spectra. The MCA was located by insonation through the temporal ultrasound window and the position with the highest signal to noise ratio (depth $48-60 \mathrm{~mm}$ ) was marked. The probe was fixed to a headband with adhesive sonography gel and data sampled at $100 \mathrm{~Hz}$ (Chart v5.2 and PowerLab; ADInstruments, Bella Vista, NSW, Australia).

\section{Cerebral and Muscle Oxygenation}

$\mathrm{ScO}_{2}$ and $\mathrm{SmO}_{2}$ were evaluated using near-infrared spectroscopy (NIRS; INVOS 5100C, Somanetics, Troy, MI, United States). For $\mathrm{ScO}_{2}$, the optode (3 and $4 \mathrm{~cm}$ emitter detector separation, wavelength 730 and $808 \mathrm{~nm}$ ) was placed over either the right or left prefrontal cortical area, in randomized order, between $\mathrm{Fp} 1$ and $\mathrm{F} 3$, or $\mathrm{Fp} 2$ and $\mathrm{F} 4$, according to the landmarks of the 10-20 system (Perrey, 2008) to avoid influence from the frontal and sagittal sinus and ipsilateral to the Doppler probe. This area of the brain is not directly involved in the neural control of movement, but deoxygenation of the prefrontal cortex has been associated with termination of exercise during both controlled and self-paced exercise (Nielsen et al., 1999; Amann et al., 2007; Seifert et al., 2009; Subudhi et al., 2009).

For $\mathrm{SmO}_{2}$ the optode was positioned on the vastus lateralis muscle of the left leg at the midpoint between the anterior superior iliac spine and the superior part of the fibula. Hair on the leg was removed for maximal optode contact and the same position of the probe was used in both trials. We considered that reductions in $\mathrm{SmO}_{2}$ and $\mathrm{ScO}_{2}$ together with cerebral perfusion would be indicative of peripheral and central fatigue, respectively.

\section{Neuromuscular Evaluation}

Neuromuscular evaluation was performed after the warm-up and immediately after the rowing trials (Figure 1). The transition time from the end of the rowing to the start of the neuromuscular evaluation was less than $10 \mathrm{~s}$. It was important to minimize this transition time because neuromuscular fatigue is strongly influenced by recovery, as all parameters recover almost linearly within $1 \mathrm{~min}$ (Vernillo et al., 2018). With this consideration, the subjects' right arm was swiftly attached to a custom designed arm-bar equipped with a calibrated strain gauge dynamometer (14-bit A/D conversion) while they were still seated on the ergometer. The shoulder and elbow of the subjects were flexed at $90^{\circ}$ with the forearm vertical and fully supinated. The dynamometer's position was adjusted in direct line with the applied force and secured at the wrist. The neuromuscular evaluation included two 4-s MVCs for determination of (averaged) elbow flexors strength, with one TMS and one motor point (MP) stimulation superimposed on each MVC, followed by another resting MP stimulation $2 \mathrm{~s}$ after each MVC to obtain peak potentiated twitch force $\left(P_{\mathrm{tw}}\right)$. Electromyographic (EMG) activity was recorded with pairs of self-adhesive surface $(10-\mathrm{mm}$ recording diameter) electrodes (Cleartrace, 1700-030, Conmed, Utica, NY, United States) placed over the muscle belly and tendons of biceps brachii, brachioradialis, and long head of triceps brachii muscles, in bipolar configuration with a $30-\mathrm{mm}$ interelectrode distance and the reference on the medial epicondyle of the humerus. Low impedance $(<5 \mathrm{k} \Omega$, controlled by a digital meter) between electrodes was achieved by shaving and gently abrading the skin and then cleaning it with isopropyl alcohol. The positions of EMG electrodes were marked with indelible ink to ensure consistent placement. The EMG signal was amplified $(\times 1,000)$, filtered $(25-1,000 \mathrm{~Hz})$, digitized, and sampled (at $5 \mathrm{kHz}$ ) to a computer using CED Micro1401 and Spike2 software (Cambridge Electronic Design, Cambridge, United Kingdom). The EMG activity was quantified as the 


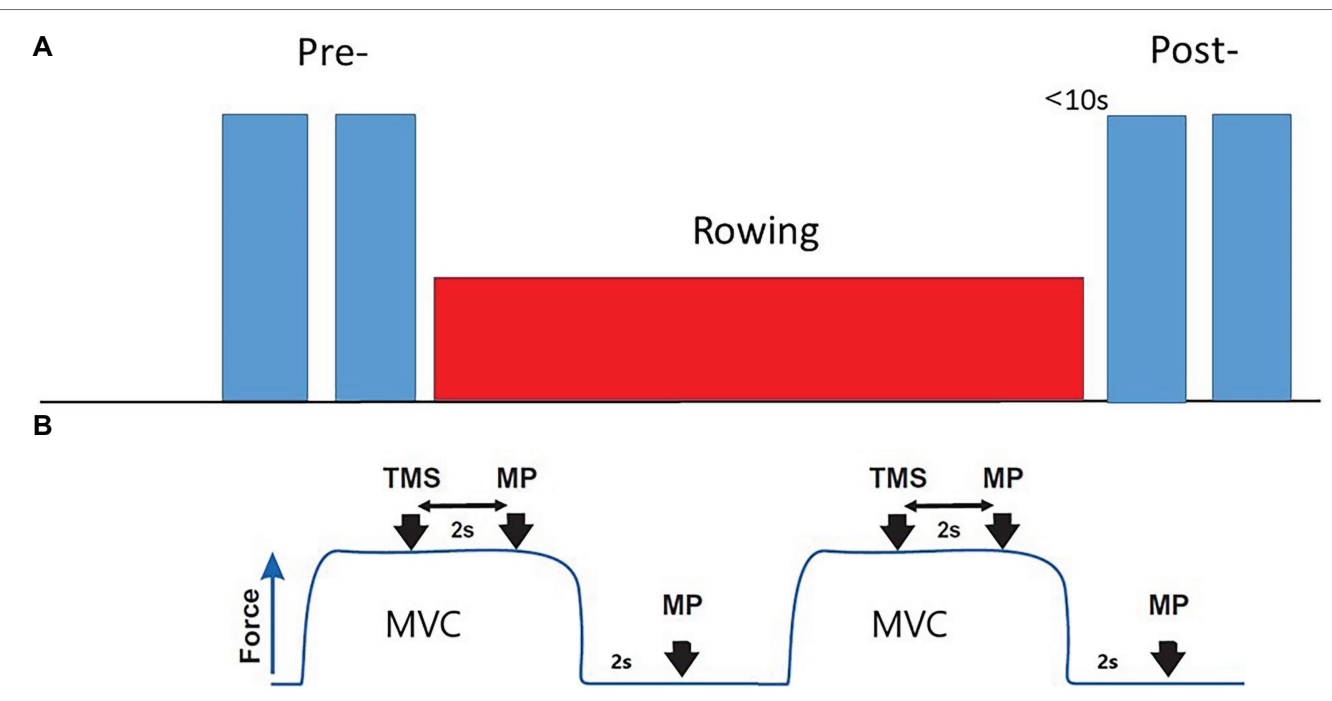

FIGURE 1 | Neuromuscular evaluation protocol. (A) Pre- baseline evaluation; Post-, After rowing (less than 10s) evaluation. (B) Each evaluation included two $4 \mathrm{~s}$ MVCs. One TMS and one MP stimulation, interspersed by $2 \mathrm{~s}$, followed by a resting MP stimulation $2 \mathrm{~s}$ after the end of contraction, were applied with each MVC.

root-mean-square value and expressed relative to the activity obtained during the control MVC.

\section{Brachial Plexus Stimulation}

Before the voluntary contractions, the size of the resting maximal compound muscle action potential (Mmax) was determined with surface EMG and used as a reference for the size of the EMG responses evoked by TMS. While the subjects were at rest single electrical stimuli of $100-\mu$ s duration were delivered to the brachial plexus via a cathode in the supraclavicular fossa (Erb's point) and an anode on the acromion. The electrical current was gradually increased until the M-wave (i.e., Mmax) of the biceps brachii no longer increased. A supramaximal stimulation current (i.e., $20 \%$ higher than that required to elicit Mmax) was used for the remainder of the experiment. The supramaximal stimulus intensitys was $136 \pm 52 \mathrm{~mA}$.

\section{Transcranial Magnetic Stimulation}

Single magnetic pulses to the motor cortex were delivered with a circular coil $(13.5 \mathrm{~cm}$ outside diameter; Magstim 200, The Magstim Co. Ltd., Whitland, Wales, United Kingdom) with its center placed at the vertex, and thus evoked motor potentials (MEPs) in the biceps brachii. The vertex was determined by marking the intersection of the measured halfway points from nasion to inion and from tragus to tragus. The optimal coil position was the site where the largest MEP was elicited, and it was marked on the scalp for consistent positioning throughout the protocol. The direction of the current flow in the coil was clockwise on the left motor cortex (postero-anterior intracranial current flow) to activate preferentially the muscles on the contralateral side. The TMS intensity was determined from a stimulus-response curve constituted of four brief consecutive contractions at 50,60,70, and $80 \%$ maximal stimulator output, in randomized order. The selected stimulus intensity was the lowest intensity eliciting maximal MEP amplitudes ( $>50 \% \mathrm{Mmax}$ ) in $\mathrm{m}$. biceps brachii (with little or no response, usually $<10-15 \%$ of Mmax, in the antagonist $\mathrm{m}$. triceps brachii) during brief voluntary contractions at $20 \%$ MVC. The TMS was always delivered once the voluntary contraction reached the intended force level and the force had stabilized.

\section{Electrical Stimulation}

For electrical stimulation of the biceps muscle, surface electrodes (Cleartrace, Conmed) were placed on each of the MPs approximately halfway from the coracoid process to the lateral epicondyle of the humerus (Park et al., 2007). A computer triggered a double $1 \mathrm{~ms}$ electrical stimulus at constant current (inter-stimuli interval: $10 \mathrm{~ms}$, DS7A Digitimer, Hertfordshire, United Kingdom). The maximal resting twitch was determined by stepwise increases in the stimulus intensity until elbow flexor twitch force failed to increase, despite an increase in stimulus intensity. Stimulation intensity was set $10-20 \%$ above the level required to produce a resting twitch of maximal amplitude and it was $122 \pm 32 \mathrm{~mA}$.

\section{Cortical Voluntary Activation $\left(\mathrm{VA}_{\mathrm{TMS}}\right)$}

Cortical voluntary activation was quantified by the force responses. Using magnetic cortical stimulation any increment in elbow flexion force evoked during an MVC (superimposed twitch) was expressed as a fraction of the amplitude of the maximal response evoked by the same stimulus in the relaxed muscle. The resting twitch was estimated by linear interpolation of the TMS induced muscle twitches obtained at 60, 80, and $100 \%$ of MVC and was identified as the $y$-intercept of the regression corresponding to the value at which voluntary force would be zero (Figure 2; Todd et al., 2003):

$$
\text { Voluntaryactivation }(\%)=\left(\frac{1-\text { superimposed twitch }}{\text { estimated resting twitch }}\right) \times 100
$$




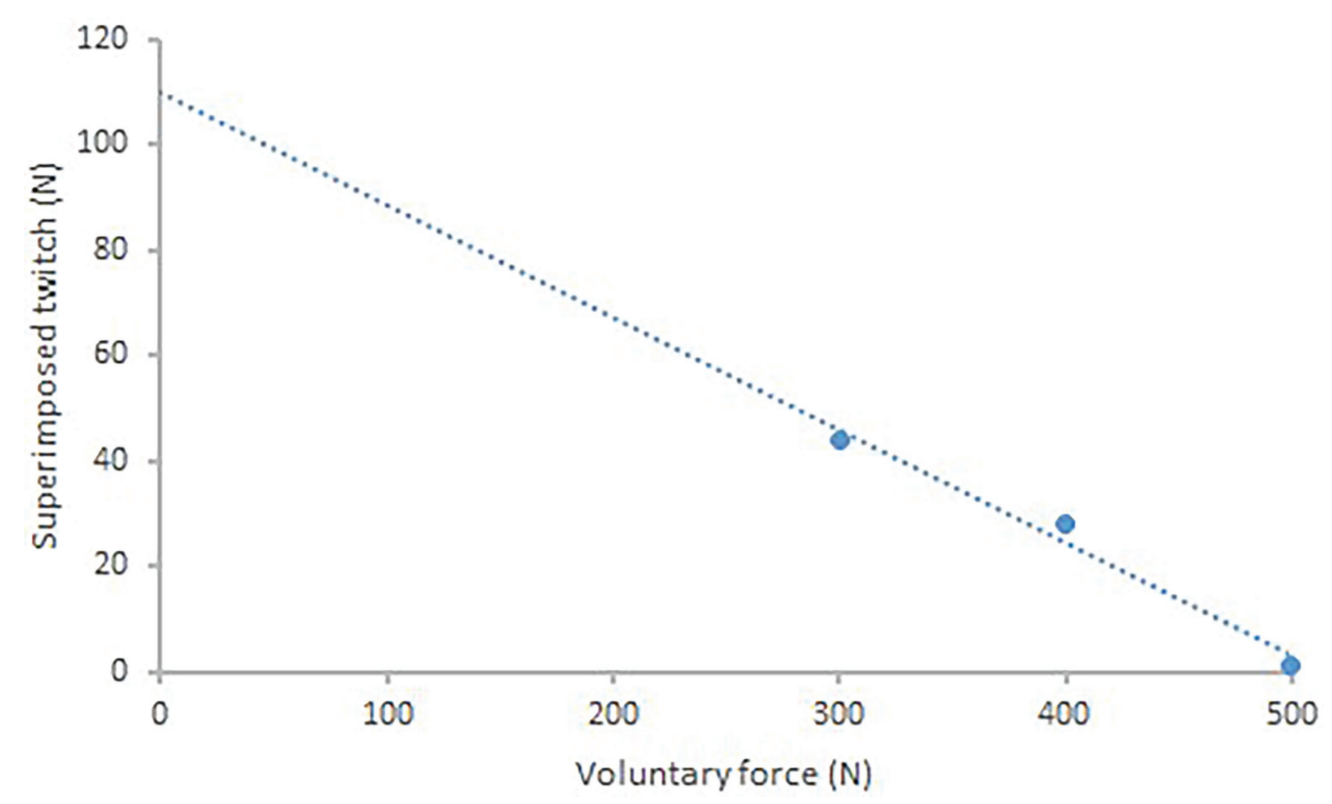

FIGURE 2 | Single subject data showing linear regression between the amplitude of the TMS superimposed twitch and voluntary force ( $r=0.99)$. The $y$-intercept $(114.5 \mathrm{~N})$ is taken as the estimated amplitude of the resting twitch.

TABLE 1 | Cerebral, cardiovascular, and respiratory variables at rest and over the last 30 s of rowing with normal and hyperoxic air.

\begin{tabular}{|c|c|c|c|c|}
\hline & \multicolumn{2}{|c|}{$21 \% \mathrm{O}_{2}$} & \multicolumn{2}{|c|}{$30 \% \mathrm{O}_{2}$} \\
\hline & Rest & Rowing & Rest & Rowing \\
\hline $\mathrm{HR}$, beats $\mathrm{min}^{-1}$ & $71 \pm 5$ & $181 \pm 2^{*}$ & $68 \pm 2$ & $178 \pm 2 *$ \\
\hline MAP, mmHg & $96 \pm 2$ & $104 \pm 4^{*}$ & $94 \pm 2$ & $109 \pm 3 *$ \\
\hline VE, L $\min ^{-1}$ & $13 \pm 1$ & $168 \pm 3^{*}$ & $13 \pm 1$ & $172 \pm 5^{*}$ \\
\hline $\mathrm{VO}_{2}, \mathrm{~L} \mathrm{~min}^{-1}$ & $0.4 \pm 0.0$ & $4.7 \pm 0.2 *$ & $0.4 \pm 0.0$ & $5.2 \pm 0.2^{*}$ \\
\hline $\mathrm{PaO}_{2}, \mathrm{mmHg}$ & $103 \pm 2$ & $94 \pm 2 *$ & $164 \pm 3$ & $161 \pm 5^{\dagger}$ \\
\hline $\mathrm{PaCO}_{2}, \mathrm{mmHg}$ & $39 \pm 1$ & $29 \pm 1 *$ & $39 \pm 1$ & $31 \pm 1^{*}$ \\
\hline $\mathrm{SaO}_{2}, \%$ & $98.3 \pm 0.2$ & $92.5 \pm 0.2 *$ & $99.4 \pm 0.1$ & $98.9 \pm 0.2^{\dagger}$ \\
\hline$M C A V_{\text {mean }}, \mathrm{cm} \mathrm{s}^{-1}$ & $52.3 \pm 8.2$ & $54.7 \pm 7.6$ & $44.7 \pm 4.0$ & $61.7 \pm 7.7^{* \dagger}$ \\
\hline $\mathrm{ScO}_{2}, \%$ & $67.3 \pm 8.2$ & $60.3 \pm 5.4^{*}$ & $66.6 \pm 3.6$ & $67.7 \pm 5.4^{\dagger}$ \\
\hline $\mathrm{SmO}_{2}, \%$ & $63.5 \pm 7.3$ & $41.2 \pm 2.0^{*}$ & $64.9 \pm 3.6$ & $48.0 \pm 3.4 * \dagger$ \\
\hline
\end{tabular}

$H R$, heart rate; MAP, mean arterial pressure; VE, ventilation; $V_{2}$, oxygen uptake; $\mathrm{PaO}_{2}$, arterial oxygen tension; $\mathrm{PaCO}_{2}$, arterial carbon dioxide tension; $M C A V_{\text {mean }}$ middle cerebral artery mean blood flow velocity; $\mathrm{SaO}_{2}$, arterial oxygen saturation; $\mathrm{ScO}_{2}$ frontal lobe oxygen saturation; $\mathrm{SmO}_{2}$, oxygenation of the vastus lateralis muscle; Values are mean $\pm S D, N=11$. *Difference compared with rest. ${ }^{\dagger}$ Difference compared with normoxia $(p<0.05)$.

Data points were excluded $(n=5.4 \%)$ when the regression of the estimated twitch was $r^{2}<0.85$.

The reliability of the TMS protocol for the determination of voluntary activation and estimated resting twitch $(\mathrm{ICC}<0.85)$ is comparable to values derived from motor nerve stimulation (Sidhu et al., 2009).

\section{Statistics}

Assumptions of sphericity (Mauchly test) and normality (ShapiroWilk test) were tested for all dependent variables. If the assumption of sphericity was violated, the corrected value for non-sphericity with Greenhouse-Geisser epsilon was reported. Values are presented as mean \pm SD.

A two-way analysis of variance (ANOVA) with repeated measures (time $\times$ trial) was used to reveal significant interactions between conditions and the Tukey post hoc test for paired data was used to locate differences. F-ratios were considered statistically significant at $p<0.05$ level and analysis was performed using SPSS Statistics 24 (IBM, Armonk, NY, United States). Descriptive statistics in the text include mean percentage change for each dependent variable, while the reported $p$ values are based on statistical comparison using absolute values.

\section{RESULTS}

In normoxia, the subjects completed the ergometer row in $6 \mathrm{~min} 56 \pm 5 \mathrm{~s}$ and hyperoxia had no significant effect compared to normoxia ( $6 \mathrm{~min} 54 \pm 4 \mathrm{~s}, 0.5 \%$ improvement). Yet, $\mathrm{VO}_{2}$ was $10.6 \%$ higher during the hyperoxic compared with the normoxic trial $\left(p<0.01\right.$, Table 1). Also, the reduction of $\mathrm{SaO}_{2}$ observed during the normoxic trial was prevented during the hyperoxic trial $(p<0.01$, Table 1$)$.

\section{Cerebrovascular Variables}

There was a significant interaction $\left[F_{(1,12)}=5.9, p<0.01\right]$ between trials and time for MCA $V_{\text {mean }}$ and $\mathrm{ScO}_{2}$. During the normoxic trial MCA $V_{\text {mean }}$, after a $4.6 \%$ increase by $1,000 \mathrm{~m}$, plateaued until the end of the trial and returned to baseline after exercise (Figure 3; Table 1). During the hyperoxic trial, MCA $V_{\text {mean }}$ increased from rest until $1,500 \mathrm{~m}$ of rowing $(38 \%$ higher, $p<0.01)$, then plateaued until the end and also returned to resting level after exercise. 


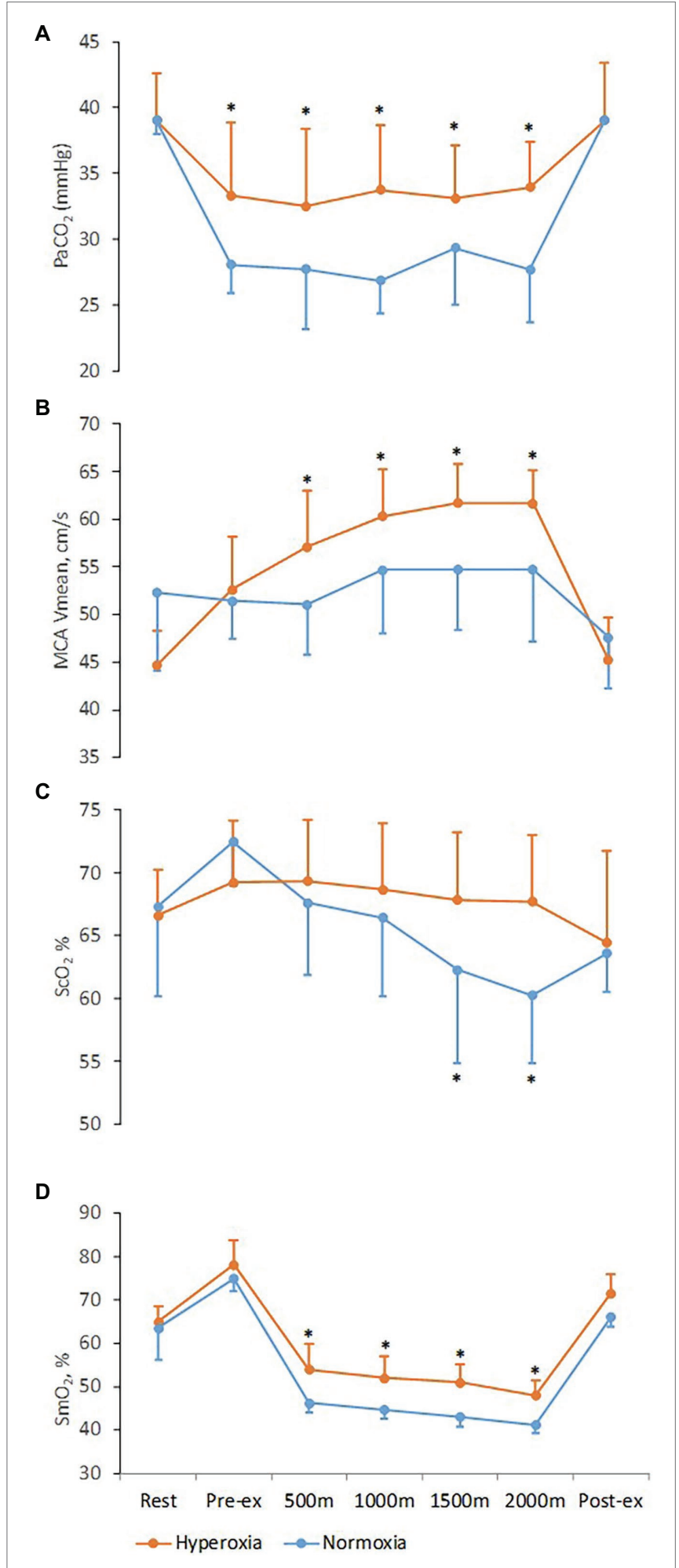

FIGURE 3 | Respiratory, cerebrovascular, and muscle variables at rest and during 2,000m all-out ergometer rowing with normoxia and hyperoxia. Pre-ex and post-ex values are obtained after the warm-up and $15 \mathrm{~min}$ into the recovery, respectively. (A) $\mathrm{PaCO}_{2}$, arterial carbon dioxide tension; (B) $M C A V_{\text {mean }}$, middle cerebral artery mean blood flow velocity; (C) $\mathrm{ScO}_{2}$, frontal lobe oxygen saturation; (D) $\mathrm{SmO}_{2}$, oxygenation of the vastus lateralis muscle. Values are means $\pm \mathrm{SD}$; *Difference between normoxic and hyperoxic trials $(N=11, p<0.05)$.
The $\mathrm{ScO}_{2}$ decreased by $7.0 \pm 4.8 \%(p<0.01)$ during the normoxic trial, while it was maintained at resting level during the hyperoxic trial (Figure 3; Table 1).

\section{Muscle Oxygenation}

There was interaction $\left[F_{(1,12)}=5.4, p<0.01\right]$ between trials and time for $\mathrm{SmO}_{2}$. During the normoxic trial, $\mathrm{SmO}_{2}$ was reduced by $26.9 \pm 2.8 \%$ by the first $500 \mathrm{~m}$ compared to rest $(p<0.001)$ and then continued to a nadir of $35.0 \pm 2.1 \%$ decrease at the end of the row $(p<0.01)$. During the hyperoxic trial, the reduction in $\mathrm{SmO}_{2}$ was attenuated to $16.8 \pm 3.0 \%(p<0.01)$ by the first $500 \mathrm{~m}$ and to a nadir of $26.1 \pm 2.4 \%(p<0.01)$ compared to rest at the end of the $2,000 \mathrm{~m}$ row (Figure 3; Table 1), indicating a $\sim 25 \%$ improvement of $\mathrm{SmO}_{2}$ compared to the normoxic trial $(p=0.03)$.

\section{Neuromuscular Function}

There was no significant difference in the MVC prior to the normoxic and hyperoxic trials $(502 \pm 15 \mathrm{~N})$. There was an interaction $\left[F_{(1,6)}=6.9, p<0.01\right]$ between trials and time for MVC. Following the normoxic trial, there was a reduction in MVC during elbow flexion $(7 \pm 3 \%, p=0.014)$ but following the hyperoxic trial the reduction was not significant $(4 \pm 3 \%$, $p=0.06$, Figure 4A).

\section{Electrical Stimulation}

There was an interaction $\left[F_{(1,2)}=19.9, p<0.01\right]$ between trials and time for $\left(P_{\mathrm{tw}}\right)$. The force evoked with direct stimulation of the motor point $\left(P_{\mathrm{tw}}\right)$ in biceps brachii at rest immediately after MVC was reduced by $31 \pm 9 \%$ following the normoxic rowing trial (pre: $140 \pm 14 \mathrm{~N}$; post: $95 \pm 12 \mathrm{~N}, p=0.005$, Figure 4B). In contrast, after the hyperoxic rowing trial, there was only a $\sim 13 \pm 4 \%$ reduction from the resting value in $P_{\mathrm{tw}}$ (pre: $148 \pm 14 \mathrm{~N}$; post: $128 \pm 12 \mathrm{~N})$ that was not statistically significant $\left[F_{(1,6)}=1.2\right.$, $p=0.21]$ and indicative of $\sim 58 \%$ attenuation of the deficit observed in the normoxic trial $(p<0.05) . P_{\mathrm{tw}}$ values before the normoxic and hyperoxic trials were similar $(p=0.52)$.

\section{Transcranial Magnetic Stimulation}

The additional force evoked with superimposed twitch on MVC was not different after rowing in normoxia. Similarly, the size of the superimposed twitch was not different before and after rowing in hyperoxia. $\mathrm{VA}_{\mathrm{TMS}}$ was not changed after the normoxic trial [pre- $99.0 \pm 1.3 \%$; post- $98.6 \pm 1.4 \% ; F_{(1,6)}=1.6, p=0.84$ ] or the hyperoxic trial (pre $98.0 \pm 1.0 \%$; post $98.5 \pm 1.2 \%, p=0.88$, Figure 4C).

\section{DISCUSSION}

This study evaluated the effect of oxygen supplementation on central and peripheral fatigue of elbow flexor muscles following maximal ergometer rowing in trained male rowers. Maximal rowing in normoxia compromised cerebral and leg muscle oxygenation and reduced arm strength that was associated with reduced force generated with direct electrical 
A

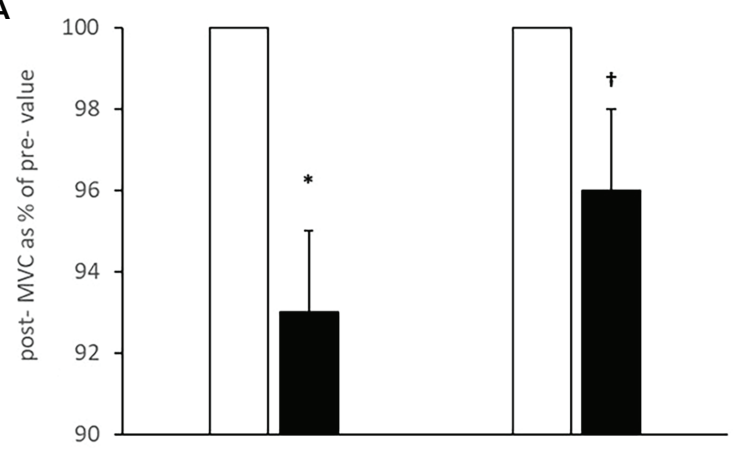

B

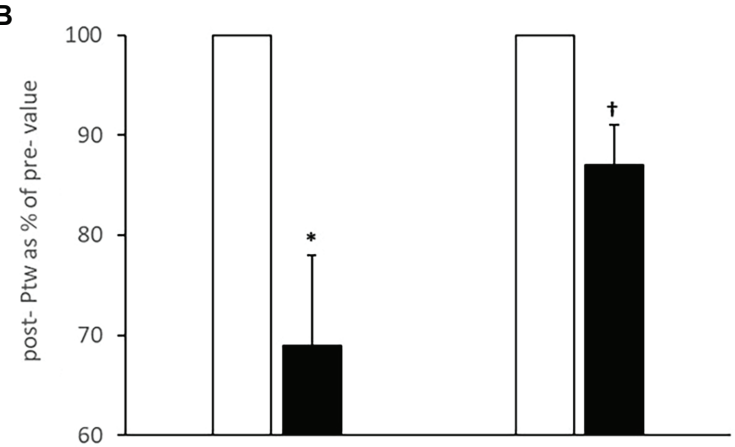

C

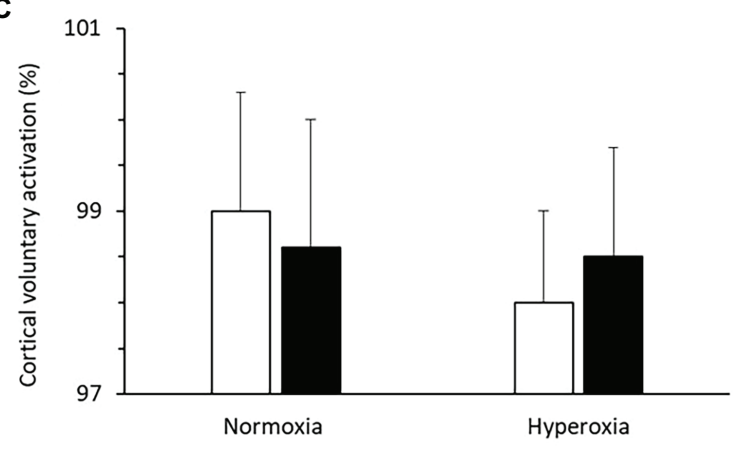

FIGURE 4 | Neuromuscular function pre- (open bars) and immediately post(closed bars) 2,000 m all-out rowing. (A) Maximal voluntary contraction (MVC) of the arm flexor muscles; (B) potentiated twitch force $\left(P_{\mathrm{tw}}\right)$; and (C) cortical voluntary activation. Values are means $\pm S D$, post-values in $(\mathbf{A}, \mathbf{B})$ are expressed as \% of pre-values; *Different from pre-value; †Different from respective value in normoxia $(N=11, p<0.05)$.

stimulation but unaltered force generated with transcranial magnetic stimulation. Supplementation with 30\% oxygen in inspired air enhanced arterial oxygen delivery, maintained cerebral oxygenation at resting level and attenuated leg muscle deoxygenation. In addition, hyperoxia attenuated the deficit in arm flexion MVC and force produced with direct electrical stimulation following the normoxic trial, while there was no effect on the force produced with transcranial magnetic stimulation. These findings demonstrate that oxygen supplementation restores cerebral oxygenation and that the attenuation of the arm strength deficit following maximal rowing is associated with peripheral rather than central fatigue mechanisms.
The present finding that arm muscle fatigue following rowing is mainly of peripheral origin is in contrast with the study by Husmann et al. (2017) that evaluated the knee extensors fatigue in elite rowers after intense rowing. Even though Husmann et al. (2017) used peripheral nerve stimulation to assess central fatigue, which provides different information from the cortical stimulation used in the present study (Todd et al., 2004), nevertheless, both methods assess whether the voluntary drive to the muscle is suboptimal for generation of maximal force. Husmann et al. (2017) observed impaired voluntary drive indicating central fatigue with no significant change in indices of peripheral fatigue. A possible explanation for this discrepancy may be offered by the unique synchronous movement pattern of the limbs during rowing. It seems that there is a central constraint that prevents recruitment of the leg muscles during the two-legged exercise inherent to rowing, while the arm muscles are not constrained by such central activation mechanism, and thus, arm muscle fatigue is likely of peripheral origin. Furthermore, such differential fatigue origin for the arms and the legs indicates that leg muscle performance is determined to a large extend by central mechanisms and, combined with the consideration that the largest amount of work during rowing is by far performed by the large leg muscles, it likely explains why an increase in $\mathrm{SaO}_{2}$, $\mathrm{SmO}_{2}$, and $\mathrm{VO}_{2} \max$ (Nielsen et al., 1998) does not necessarily increase the amount of work performed.

In agreement with the present findings, studies on exerciseinduced fatigue that used self-paced whole body exercise of similar duration with the present study (Amann et al., 2006a; Thomas et al., 2015; 5 and $4 \mathrm{~km}$ cycling time trials, respectively) suggest that the contribution of central vs. peripheral fatigue is shifted peripherally in short exercise trials $(\sim 6 \mathrm{~min})$. In contrast, the observation that the contribution of central vs. peripheral fatigue is shifted centrally with increasing severity of arterial hypoxemia (Amann et al., 2007) suggests central fatigue following maximal rowing (Nielsen et al., 1999). Furthermore, the association of central fatigue with inhibition of slow muscle fiber recruitment (Rasmussen et al., 2007) that are abundant in rowers (Volianitis et al., 2020) supports a contribution of central fatigue to rowing performance. A possible explanation of our finding of a primarily peripheral contribution to arm muscle fatigue may be that exercise-induced fatigue is primarily central below 70-75\% $\mathrm{SaO}_{2}$ (Amann et al., 2007), while in our study $\mathrm{SaO}_{2}$ was attenuated only to $92.5 \%$ during rowing in normoxia.

Oxygen supplementation prevented the moderate arterial desaturation $(\sim 7 \%)$ and maintained $\mathrm{SaO}_{2}$ at resting levels. Consequently, peripheral arm fatigue was reduced by more than half, in agreement with the effect of hyperoxia on quadriceps fatigue (Amann et al., 2006b; Romer et al., 2006). However, besides the effect on peripheral muscle fatigue oxygen supplementation increased $\mathrm{VO}_{2} \max$ by $\sim 11 \%$ in agreement with previous rowing studies (Peltonen et al., 1995; Nielsen et al., 1999; Volianitis et al., 2008), which is suggestive of central (i.e., cardiovascular) rather than 
peripheral (i.e., muscular) limitation to rowing performance, albeit work output performed was not increased significantly. Presumably, the restoration of $\mathrm{ScO}_{2}$ would attenuate the motor activation limitations associated with cerebral deoxygenation (Rasmussen et al., 2007; i.e., one possible factor of central fatigue) providing support to the notion of central origin to rowing fatigability. On the other hand, the level of cerebral deoxygenation in the present study is small compared with other studies (González-Alonso et al., 2004) suggesting that the subjects could tolerate even higher degree of cerebral deoxygenation. This consideration is supported by that the TMS evaluation did not confirm our presumption of central fatigue in normoxia, and therefore, there was no significant deficit in central motor activation that could be attenuated with oxygen supplementation. It should also be acknowledged that since women exhibit different fatigue characteristics than men (f.x. less fatigable when sustaining a contraction at the same relative intensity; Hicks et al., 2001), our findings on male rowers may not be applicable to the same extent in female rowers.

The $\mathrm{O}_{2}$ supplementation also increased MCA $V_{\text {mean }}$ by $\sim 13 \%$ compared to normoxia, a response that can be explained by the higher $\mathrm{PaCO}_{2}(\sim 2 \mathrm{mmHg})$ during the hyperoxic trial. However, this elevated MCA $V_{\text {mean }}$ did not enhance rowing performance by increasing cerebral oxygen delivery, as has been shown also for incremental cycling performance (Smith et al., 2012). Taken together, these findings support the postulate that increasing cerebral oxygen delivery above what is required to maintain cerebral metabolism has little to no positive effect on performance, as expressed by Smith (2016).

The elevation of $\mathrm{SmO}_{2}$ with $\mathrm{O}_{2}$ supplementation is concomitant with the attenuation of the decline of electrically twitch-evoked force after MVC, suggesting that muscle oxygenation is associated with the attenuation of peripheral fatigue in the hyperoxic trial. Abolishment of the $\mathrm{ScO}_{2}$ deoxygenation, while only partial recovery of $\mathrm{SmO}_{2}$ deoxygenation, with $\mathrm{O}_{2}$ supplementation is in agreement with suggestions that hyperoxia has a larger effect on attenuating the decrease in cerebral rather than muscle oxygenation (Nielsen et al., 1999; Oussaidene et al., 2013). The MVC was reduced following rowing with normoxia but not significantly so with hyperoxia. However, since a MVC is the sum of the motor systems performance including the efficacy of the central nervous system and of the contractile apparatus (Gandevia, 2001), MVC does not allow for separation between central and peripheral (muscle) fatigue.

\section{Strengths and Limitations}

The strength of the present study is the use of an externally valid whole body dynamic exercise model to evaluate neuromuscular fatigue of a muscle group, combined with evaluation of cerebral and muscle oxygenation values providing an integrative depiction of rowing performance and fatigability. The participants are all competitive rowers at national/ international level ensuring that the contribution of the muscle group evaluated (arm) to the whole body skilled performance is valid and thus enhance generalization of the findings.

The limitations inherent to evaluations of fatigue postexercise also apply to our study. The need for a quick measurement post-fatigue is somehow incompatible with the necessity to perform several contractions to provide a reliable evaluation of MVCs or evoked contractions. The elusive nature of fatigue is affected critically by the rapid recovery of most fatigue indices and thus our findings should be interpreted in a relative context applicable to intra-subject comparisons with similar evaluation delay, rather than absolute values and comparisons across subjects or studies. Also, it has to be recognized that the locus of neuromuscular fatigue of a muscle group does not necessarily translate to fatigability in rowing performance.

\section{CONCLUSIONS AND PERSPECTIVES}

In conclusion, the evaluations of $\mathrm{ScO}_{2}, \mathrm{SmO}_{2}, \mathrm{MCA}$, and $\mathrm{VO}_{2}$ during rowing support a central component to fatigability in agreement with the study by Husmann et al. (2017). Yet, evaluation by electrical and transcranial magnetic stimulation of the elbow flexors indicate peripheral fatigue that is attenuated with $\mathrm{O}_{2}$ supplementation. Overall, even though evaluation of some fatigability indices point to a central limitation of rowing performance, that seems not to be the case for the arm muscles.

\section{DATA AVAILABILITY STATEMENT}

The raw data supporting the conclusions of this article will be made available by the authors, without undue reservation.

\section{ETHICS STATEMENT}

The studies involving human participants were reviewed and approved by Ethics Committee of Copenhagen (KF 01287471). The patients/participants provided their written informed consent to participate in this study.

\section{AUTHOR CONTRIBUTIONS}

SV, PR, NP, and NS contributed to the study design, data collection and analysis, and manuscript writing. All authors have read and approved the final version of the manuscript and agreed with the order of presentation of the authors.

\section{ACKNOWLEDGMENTS}

We thank M. Bjarrum, C. Carlson, A. Overgaard, and A. Fabricius-Bjerre for valuable contribution in conducting the study. 


\section{REFERENCES}

Allen, G. M., Gandevia, S. C., and McKenzie, D. K. (1995). Reliability of measurements of muscle strength and voluntary activation using twitch interpolation. Muscle Nerve 18, 593-600. doi: 10.1002/mus.880180605

Allen, D. G., Lamb, G. D., and Westerblad, H. (2008). Skeletal muscle fatigue: cellular mechanisms. Physiol. Rev. 88, 287-332. doi: 10.1152/ physrev.00015.2007

Amann, M., Eldridge, M. W., Lovering, A. T., Stickland, M. K., Pegelow, D. F., and Dempsey, J. A. (2006a). Arterial oxygenation influences central motor output and exercise performance via effects on peripheral locomotor muscle fatigue in humans. J. Physiol. 575, 937-952. doi: 10.1113/ jphysiol.2006.113936

Amann, M., Romer, L. M., Pegelow, D. F., Jacques, A. J., Hess, C. J., and Dempsey, J. A. (2006b). The effects of arterial oxygen content upon peripheral locomotor muscle fatigue. J. Appl. Physiol. 101, 119-127. doi: 10.1152/ japplphysiol.01596.2005

Amann, M., Romer, L. M., Subudhi, A. W., Pegelow, D. F., and Dempsey, J. A. (2007). Severity of arterial hypoxaemia affects the relative contributions of peripheral muscle fatigue to exercise performance in healthy humans. $J$. Physiol. 581, 389-403. doi: 10.1113/jphysiol.2007.129700

Dominelli, P. B., Molgat-Seon, Y., Griesdale, D., Peters, C. M., Blouin, J. S., Sekhon, M., et al. (2017). Exercise-induced quadriceps muscle fatigue in men and women: effects of arterial oxygen content and respiratory muscle work. J. Physiol. 595, 5227-5244. doi: 10.1113/JP274068

Enoka, R. M., Baudry, S., Rudroff, T., Farina, D., Klass, M., and Duchateau, J. (2011). Unraveling the neurophysiology of muscle fatigue. J. Electromyogr. Kinesiol. 21, 208-219. doi: 10.1016/j.jelekin.2010.10.006

Enoka, R. M., and Duchateau, J. (2016). Translating fatigue to human performance. Med. Sci. Sports Exerc. 48, 2228-2238. doi: 10.1249/MSS.0000000000000929

Gandevia, S. C. (2001). Spinal and supraspinal factors in human muscle fatigue. Physiol. Rev. 81, 1725-1789. doi: 10.1152/physrev.2001.81.4.1725

González-Alonso, J., Dalsgaard, M. K., Osada, T., Volianitis, S., Dawson, E. A., Yoshiga, C. C., et al. (2004). Brain and central haemodynamics and oxygenation during maximal exercise in humans. J. Physiol. 557, 331-342. doi: 10.1113/ jphysiol.2004.060574

Hicks, A. L., Kent-Braun, J., and Ditor, D. S. (2001). Sex differences in human skeletal muscle fatigue. Exerc. Sport Sci. Rev. 29, 109-112. doi: 10.1097/ 00003677-200107000-00004

Husmann, F., Gube, M., Felser, S., Weippert, M., Mau-Moeller, A., Bruhn, S., et al. (2017). Central factors contribute to knee extensor strength loss after 2000-m rowing in elite male and female rowers. Med. Sci. Sports Exerc. 49, 440-449. doi: 10.1249/MSS.0000000000001133

Katayama, K., Amann, M., Pegelow, D. F., Jacques, A. J., and Dempsey, J. A. (2007). Effect of arterial oxygenation on quadriceps fatigability during isolated muscle exercise. Am. J. Phys. 292, R1279-R1286. doi: 10.1152/ajpregu.00554. 2006

Koral, J., Oranchuk, D. J., Wrightson, J. G., Twomey, R., and Millet, G. Y. (2020). Mechanisms of neuromuscular fatigue and recovery in unilateral versus bilateral maximal voluntary contractions. J. Appl. Physiol. 128, 785-794. doi: 10.1152/japplphysiol.00651.2019

Nielsen, H. B., Boushel, R., Madsen, P., and Secher, N. H. (1999). Cerebral desaturation during exercise reversed by $\mathrm{O}_{2}$ supplementation. Am. J. Physiol. 277, H1045-H1052. doi: 10.1152/ajpheart.1999.277.3.H1045

Nielsen, H. B., Madsen, P., Svsendsen, L. B., Roach, R. C., and Secher, N. H. (1998). The influence of $\mathrm{PaO}_{2}, \mathrm{pH}$ and $\mathrm{SaO}_{2}$ on maximal oxygen uptake. Acta Physiol. Scand. 164, 89-97. doi: 10.1046/j.1365-201X.1998. 00405.x

Nybo, L., and Rasmussen, P. (2007). Inadequate cerebral oxygen delivery and central fatigue during strenuous exercise. Exerc. Sport Sci. Rev. 35, 110-118. doi: 10.1097/jes.0b013e3180a031ec

Oussaidene, K., Prieur, F., Bougault, V., Borel, B., Matran, R., and Mucci, P. (2013). Cerebral oxygenation during hyperoxia-induced increase in exercise tolerance for untrained men. Eur. J. Appl. Physiol. 113, 2047-2056. doi: 10.1007/s00421-013-2637-4

Park, B. K., Shin, Y. B., Ko, H. Y., Park, J. H., and Baek, S. Y. (2007). Anatomic motor point localization of the biceps brachii and brachialis muscles. $J$. Korean Med. Sci. 22, 459-462. doi: 10.3346/jkms.2007.22.3.459
Peltonen, J. E., Rantamäki, J., Niittymäki, S. P., Sweins, K., Viitasalo, J. T., and Rusko, H. K. (1995). Effects of oxygen fraction in inspired air on rowing performance. Med. Sci. Sports Exerc. 27, 573-579.

Perrey, S. (2008). Non-invasive NIR spectroscopy of human brain function during exercise. Methods 45, 289-299. doi: 10.1016/j.ymeth.2008. 04.005

Rasmussen, P., Dawson, E. A., Nybo, L., van Lieshout, J. J., Secher, N. H., and Gjedde, A. (2007). Capillary-oxygenation-level-dependent near-infrared spectrometry in frontal lobe of humans. J. Cereb. Blood Flow Metab. 27, 1082-1093. doi: $10.1038 /$ sj.jcbfm. 9600416

Rasmussen, P., Nielsen, J., Overgaard, M., Krogh-Madsen, R., Gjedde, A., Secher, N. H., et al. (2010). Reduced muscle activation during exercise related to brain oxygenation and metabolism in humans. J. Physiol. 588, 1985-1995. doi: 10.1113/jphysiol.2009.186767

Romer, L. M., Haverkamp, H. C., Lovering, A. T., Pegelow, D. F., and Dempsey, J. A. (2006). Effect of exercise-induced arterial hypoxemia on quadriceps muscle fatigue in healthy humans. Am. J. Phys. 290, R365-R375. doi: 10.1152/ ajpregu.00332.2005

Rossman, M. J., Venturelli, M., McDaniel, J., Amann, M., and Richardson, R. S. (2012). Muscle mass and peripheral fatigue: a potential role for afferent feedback? Acta Physiol. 206, 242-250. doi: 10.1111/j.1748-1716.2012. 02471.x

Secher, N. H. (1975). Isometric rowing strength of experienced and inexperienced oarsmen. Med. Sci. Sports 7, 280-283.

Secher, N. H., Rube, N., and Elers, J. (1988). Strength of two- and one-leg extension in man. Acta Physiol. Scand. 134, 333-339. doi: 10.1111/j.1748-1716. 1988.tb08500.x

Secher, N. H., Seifert, T., and Van Lieshout, J. J. (2008). Cerebral blood flow and metabolism during exercise: implications for fatigue. J. Appl. Physiol. 104, 306-314. doi: 10.1152/japplphysiol.00853.2007

Seifert, T., Rasmussen, P., Secher, N. H., and Nielsen, H. B. (2009). Cerebral oxygenation decreases during exercise in humans with beta-adrenergic blockade. Acta Physiol (Oxford) 196, 295-302. doi: 10.1111/j.1748-1716. 2008.01946.x

Sidhu, S. K., Bentley, D. J., and Carroll, T. J. (2009). Cortical voluntary activation of the human knee extensors can be reliably estimated using transcranial magnetic stimulation. Muscle Nerve 39, 186-196. doi: 10.1002/ mus. 21064

Smith, K. J. (2016). Fuelling cortical excitability during exercise: what's the matter with delivery? J. Physiol. 594, 5047-5048. doi: 10.1113/ JP272756

Smith, K. J., Wong, L. E., Eves, N. D., Koelwyn, G. J., Smirl, J. D., Willie, C. K., et al. (2012). Regional cerebral blood flow distribution during exercise: influence of oxygen. Respir. Physiol. Neurobiol. 184, 97-105. doi: 10.1016/j. resp.2012.07.014

Subudhi, A. W., Miramon, B. R., Granger, M. E., and Roach, R. C. (2009). Frontal and motor cortex oxygenation during maximal exercise in normoxia and hypoxia. J. Appl. Physiol. 106, 1153-1158. doi: 10.1152/japplphysiol. 91475.2008

Thomas, K., Goodall, S., Stone, M., Howatson, G., St. Clair Gibson, A., and Ansley, L. (2015). Central and peripheral fatigue in male cyclists after 4-, 20-, and 40-km time trials. Med. Sci. Sports Exerc. 47, 537-546. doi: 10.1249/ MSS.0000000000000448

Todd, G., Taylor, J. L., and Gandevia, S. C. (2003). Measurement of voluntary activation of fresh and fatigued human muscles using transcranial magnetic stimulation. J. Physiol. 551, 661-671. doi: 10.1113/jphysiol.2003. 044099

Todd, G., Taylor, J. L., and Gandevia, S. C. (2004). Reproducible measurement of voluntary activation of human elbow flexors with motor cortical stimulation. J. Appl. Physiol. 97, 236-242. doi: 10.1152/japplphysiol 01336.2003

Vernillo, G., Temesi, J., Martin, M., and Millet, G. Y. (2018). Mechanisms of fatigue and recovery in upper versus lower limbs in men. Med. Sci. Sports Exerc. 50, 334-343. doi: 10.1249/MSS.0000000000001445

Volianitis, S., Fabricius-Bjerre, A., Overgaard, A., Strømstad, M., Bjarrum, M., Carlson, C., et al. (2008). The cerebral metabolic ratio is not affected by oxygen availability during maximal exercise in humans. J. Physiol. 586, 107-112. doi: 10.1113/jphysiol.2007.142273 
Volianitis, S., and Secher, N. H. (2009). Rowing, the ultimate challenge to the human body - implications for physiological variables. Clin. Physiol. Funct. Imaging 29, 241-244. doi: 10.1111/j.1475-097X.2009.00867.x

Volianitis, S., Secher, N. H., and Quistorff, B. (2018). Elevated arterial lactate delays recovery of intracellular muscle $\mathrm{pH}$ after exercise. Eur. J. Appl. Physiol. 118, 2429-2434. doi: 10.1007/s00421-018-3969-x

Volianitis, S., Yoshiga, C. C., and Secher, N. H. (2020). The physiology of rowing with perspective on training and health. Eur. J. Appl. Physiol. 120, 1943-1963. doi: 10.1007/s00421-020-04429-y

Conflict of Interest: The authors declare that the research was conducted in the absence of any commercial or financial relationships that could be construed as a potential conflict of interest.
Publisher's Note: All claims expressed in this article are solely those of the authors and do not necessarily represent those of their affiliated organizations, or those of the publisher, the editors and the reviewers. Any product that may be evaluated in this article, or claim that may be made by its manufacturer, is not guaranteed or endorsed by the publisher.

Copyright (c) 2022 Volianitis, Rasmussen, Petersen and Secher. This is an openaccess article distributed under the terms of the Creative Commons Attribution License (CC BY). The use, distribution or reproduction in other forums is permitted, provided the original author(s) and the copyright owner(s) are credited and that the original publication in this journal is cited, in accordance with accepted academic practice. No use, distribution or reproduction is permitted which does not comply with these terms. 